\title{
Distribution and orientation of steel fibres in steel fibre reinforced concrete
}

\author{
Olubisi Ige, Stephanie Barnett, Ayman Nassif, John Williams
}

\begin{abstract}
The use of fibres to reinforce brittle materials for better performance has been employed since time immemorial. Therefore, inclusion of steel fibres in concrete has always improved the post-cracking strength and concrete ductility to a large extent while full potential of steel fibre reinforced concrete (SFRC) is still yet to be exploited in practice. This study investigated the effects of fibre type, dosage and maximum aggregate size on distribution and orientation and hence, the flexural performance of steel fibre reinforced concrete. Hooked-end steel fibres with $50 \mathrm{~mm}$ and $60 \mathrm{~mm}$ length, aspect ratio of 45,65 and 80 , and dosages of $0 \mathrm{~kg} / \mathrm{m}^{3}, 25$ $\mathrm{kg} / \mathrm{m}^{3}, 40 \mathrm{~kg} / \mathrm{m}^{3}, 50 \mathrm{~kg} / \mathrm{m}^{3}$ and $60 \mathrm{~kg} / \mathrm{m}^{3}$ were used with maximum sizes of coarse aggregate of $10 \mathrm{~mm}$ and $20 \mathrm{~mm}$. $X$-ray Computed Tomography was employed for imaging cores taken from the slab specimens after testing. The experimental results show a remarkable improvements in flexural strength up to $83 \%$ observed at larger dosage of steel fibre and when good interaction leading to better distribution and orientation of fibres within concrete matrix is sustained between right fibre geometry and appropriately sized aggregate.
\end{abstract}

Keywords-Concrete, Flexural properties, Steel fibres, Aggregate size, Fibre distribution and orientation.

\section{Introduction}

Concrete is the most important bulk material in construction industries all over the world. However, its brittle nature mode of failure is undesirable. The tensile strength of concrete is very low when compared to its compressive strength. For this reason, concrete has continued to undergo persistent development with various types of concrete developed through the ages while research is still ongoing to find the lasting solution to its brittle nature of failure. This challenge is being met with the evolution of steel fibre reinforced concrete (SFRC) which contains thin steel fibres spread throughout the mass in order to obtain multi-directional reinforcement with main objective of modifying the properties of concrete by improving the tensile or flexural strength, improving the impact strength and toughness, controlling cracking and the mode of failure by means of post-cracking ductility and improving durability $[1,2]$.

Investigations carried out in the past have found hooked end steel fibres to show the best result in post cracking strength and ductility of SFRC exhibiting higher values of toughness and residual strength as compared to all other types of fibres [3, 4]. Also, effects of fibre aspect ratio (ratio of length to diameter of fibres) and dosage in concrete matrix on the mechanical properties of steel fibre reinforced concrete have been investigated. Fibres with high aspect ratio have been suggested to give a better improvement in the post cracking behaviour while the higher the dosage of

Olubisi Ige, Stephanie Barnett, Ayman Nassif, John Williams University of Portsmouth

United Kingdom steel fibres within the concrete matrix, the better the flexural strength. However, the compressive strength of concrete is observed to be only slightly improved with the addition of steel fibre $[1,5]$.

The effects of aggregate size in steel fibre reinforced concrete matrix has been observed to be a factor to consider when considering the post-elastic property changes of the composite material [6]. The behaviour of steel fibre in flowing concrete are not only affected by their length and shape, but also by their interaction with coarse aggregate particles which might in turn alter their orientation in concrete [7].

It has been reported that steel fibres can be combined with conventional reinforcement in order to control cracking, and hence reducing the amount of bars required in some applications such as water retaining structures in which it is necessary in the design to control the width of early-age thermal cracks. Also, it was stated that a reduction in the amount of reinforcement is possible up to 50\%, while still maintaining the same crack width in some applications. It further ascertained that fibres are increasingly being used to replace conventional steel fabric in ground bearing slabs, beam-column joints of rigid-framed railway bridges and in some cases replacing all, in suspended ground floor slabs on piles $[8,9]$. This advancement has really increased rapidly the use of steel fibre reinforced concrete in civil and engineering applications around the world. Examples are in industrial ground floor slabs where number of joints have been reduced or eliminated, in sprayed concrete for mine and tunnel lining, in thin shell dome construction, harbour and airport pavement.

However, despite the fact that SFRC is used for a wide variety of applications, the design codes for its structural elements are not presently available. Though, the technology is still evolving and guidelines are under development, the use of SFRC has been limited in many areas [1, 10]. Meanwhile, fibre distribution and orientation has been reported to have a very significant effect on the flexural strength and other mechanical properties of the composite material and hence, should be considered during structural design of steel reinforced material, [7].

\section{Research Significance}

It may be difficult to optimize the maximum contribution of the steel fibres to the crack width control mechanism without a proper investigation of how fibres are distributed within the concrete and their orientation in the direction of stresses. Therefore, there is need for more research of how individual components of this composite material behave and interact to improve understanding of its behaviour at a structural level. More understanding of the internal mechanism, flexural properties and general workings of steel fibre reinforced concrete is needed to fully exploit this potential in practice. 
Proc. Of the International Conference on Advances in Civil, Structural and Construction Engineering - CSCE 2016 Copyright @ Institute of Research Engineers and Doctors. All rights reserved.

ISBN: 978-1-63248-101-6 doi: 10.15224/ 978-1-63248-101-6-10

Notwithstanding many studies on SFRC with results showing relationship between post-cracking strength and fibre volume, type, geometry, and with varying specimen geometry and binder formulation, the experimental results on monitor of distribution and orientation of steel fibres in SFRC and how the positioning affects the maximum output of the resulting material are considered few.

This research work studies the effects of fibre geometry, dosage and coarse aggregate size on the behaviour of fibres within the concrete matrix and the subsequent influence on how fibres are orientated and distributed and hence, the effects on flexural properties of steel fibre reinforced concrete.

\section{Experimental Programme}

The experimental programme for this study was structured to include investigation of mechanical performance of SFRC and scanning of cores extracted from slab specimens by X-ray computed tomography (CT). The techniques used allowed investigation of mechanical performance of SFRC and the distribution and orientation of the fibres within the matrix, in order to evaluate the links between the two. The experimental campaign also monitors the correlation between the internal mechanism of steel fibres in concrete matrix and flexural properties of steel fibres reinforced concrete, exploring different avenues for validation and consolidation of the different experimental outcomes.

\section{A. Selected Variables}

The variables selected for this study were those considered to influence how steel fibres and concrete matrix associate together during mixing, affecting the positioning of steel fibres within the SFRC. The experimental variables were fibre length and aspect ratio, fibre dosage and maximum aggregate size. Fibre lengths of $50 \mathrm{~mm}$ and 60 $\mathrm{mm}$, aspect ratio (ratio of length to diameter of fibre) of 45 , 65 and 80 , and dosages of $0 \mathrm{~kg} / \mathrm{m}^{3}, 25 \mathrm{~kg} / \mathrm{m}^{3}, 40 \mathrm{~kg} / \mathrm{m}^{3}, 50$ $\mathrm{kg} / \mathrm{m}^{3}$ and $60 \mathrm{~kg} / \mathrm{m}^{3}$ by mass were used with maximum sizes of coarse aggregate of $10 \mathrm{~mm}$ and $20 \mathrm{~mm}$. Dramix hooked end type of steel fibres supplied by Bekaert (steel fibre manufacturing company) were used for the investigation. Steel fibres of $50 \mathrm{~mm}$ length are as shown in Fig 1. Three different types were investigated, designated 45/50, 65/60 and $80 / 60$ (where the two numbers refer to the aspect ratio and length of the fibre respectively).

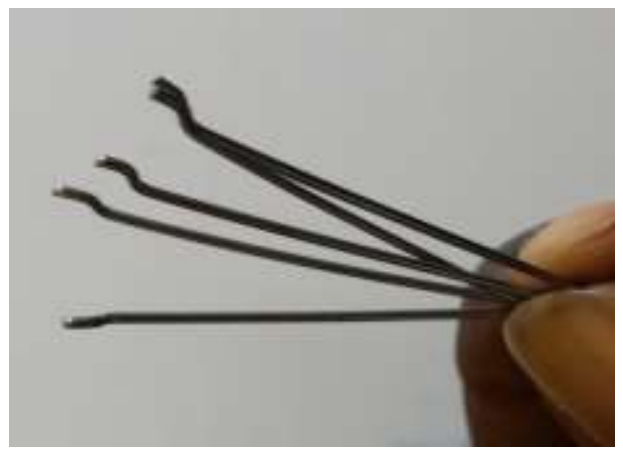

Figure 1. Hooked end steel fibres

\section{B. Materials and Procedure}

All the mixtures were prepared by the same materials. Portland cement (CEM 1 52.5R), complying with BS EN 197-1 [11], tap water, polycarboxylate polymer-based superplasticizer to give good workability at the low water/cement ratio employed and sea-won coarse and fine aggregates were used in the mixes. Water/cement ratio of 0.5 was used for this study. The same mix proportion of concrete was used in the study to allow for uniformity and proper comparison. Mixing of the concrete was accomplished by pan mixer of $0.05 \mathrm{~m}^{3}$ capacity, adopting a particular procedure for all mixes so as to achieve a uniform and better dispersion of fibres in the mix and also to avoid balling effect; gravel, sand and cement were placed into the mixer and dried mixed for 3 minutes, then water was added in the space of one minute immediately followed by superplasticizer and allowed to mix for another 3 minutes. The fibres were added last and then a further 1 to 2 minutes mixing was allowed to have the material sufficiently mixed. The mix proportion for both plain concrete and steel fibre reinforced concrete as shown in Table 1 was used in the study with addition of different dosages of steel fibres of 25 $\mathrm{kg} / \mathrm{m}^{3}, 40 \mathrm{~kg} / \mathrm{m}^{3}, 50 \mathrm{~kg} / \mathrm{m}^{3}$ and $60 \mathrm{~kg} / \mathrm{m}^{3}$ by mass.

TABLE1. MIX PROPORTIONS OF CONCRETE

\begin{tabular}{|l|c|}
\hline Material & $\begin{array}{c}\text { Quantity } \\
\left(\mathrm{kg} / \mathrm{m}^{3}\right)\end{array}$ \\
\hline Cement, CEM 1 & 310 \\
\hline Sand & 786 \\
\hline Gravel & 1179 \\
\hline Free water & 155 \\
\hline Superplasticizer & 1 \\
\hline
\end{tabular}

In the first series of experiments, the freshly mixed plain concrete and steel fibre reinforced concrete were cast into $100 \mathrm{~mm}$ cubes and beam specimens of $150 \mathrm{~mm}$ by $150 \mathrm{~mm}$ by $600 \mathrm{~mm}$ for each mix of three replicate samples. In a second series of experiments, concrete slab specimens of $600 \mathrm{~mm}$ by $600 \mathrm{~mm}$ by $100 \mathrm{~mm}$ were made, maintaining the same concrete mix proportions and variables apart from the fibre dosages being fixed at $50 \mathrm{~kg} / \mathrm{m}^{3}$ for flexural testing. The slab specimens were in three replicates for each fibre/aggregate size combination mix. Fig. 2 shows the steel fibre reinforced concrete freshly cast into the cube and beam moulds while Fig. 3 shows the slab specimen in the square mould.

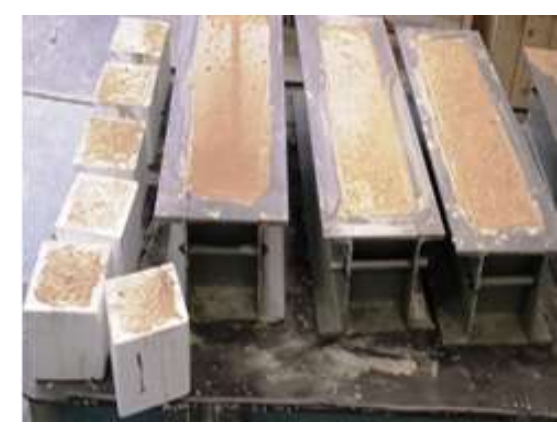

Figure 2. Fresh SFRC in beams and cubes moulds 


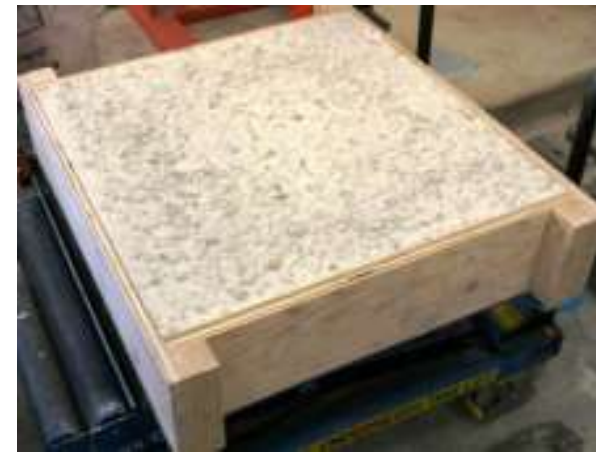

Figure 3. Casting of slab specimen

Compaction of all specimens was done using a vibrating table for a short period of about one minute to avoid segregation of the fibres in the matrix. Curing of the cube and beam specimens after demoulding at 24 hours was done by storing them in a water tank at $20 \pm 2{ }^{\circ} \mathrm{C}$ while that of slabs was accomplished by covering with polythene sheet and continuous wetting until testing at 28 days

\section{Test Setup}

The compressive strength tests were measured on the $100 \mathrm{~mm}$ cubes using ADR - Autotest machine of $2000 \mathrm{KN}$ maximum capacity while the beam specimens and slabs were tested for flexural properties using a computer controlled closed-loop servo hydraulic Zwick/Roell Z250 equipment with maximum capacity of $250 \mathrm{KN}$. All the tests were carried out at 28 days. The beam specimens were tested under three point loading, as shown in Fig. 4 with notches introduced in the middle section to a depth of 25 $\mathrm{mm}$ by a diamond saw before testing. A crack mouth opening displacement (CMOD) gauge was positioned in the notch to control the test at the CMOD rates specified by BS EN 14651, [12].

The square panels were tested at 28 days as specified by BS EN 14488-5, [13]. The test was accomplished using a Zwick/Roell $250 \mathrm{KN}$ Universal Testing Machine with a rigid steel square loading block having a contact surface of $100 \mathrm{~mm} \times 100 \mathrm{~mm}$ and thickness of $25 \mathrm{~mm}$, which was positioned at the centre of the upper face of the concrete slab. The testing machine was a displacement controlled, hydraulic universal testing machine with a capacity of 250 KN while a linear variable displacement transducer (LVDT) was positioned beneath the centre of the specimen to record the deflection.

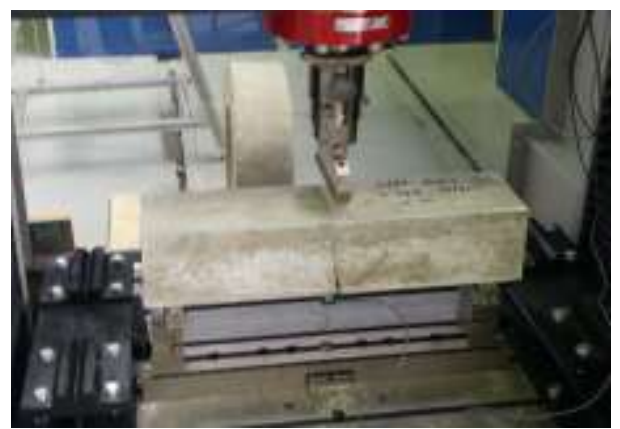

Figure 4. Three-point loading test of beam specimen
Two core samples of $100 \mathrm{~mm}$ diameter were extracted from each of the square panel after flexural test has been carried out on them. In order to assess the effects of the chosen variables on fibre distribution and orientation and the subsequent effects on mechanical performance of the material, X-ray computed tomography (CT) imaging was carried out on the core samples using a $350 \mathrm{kV}$ X-ray source. The resulting data generated was then transferred to algorithms which reconstructed the image. Insight software is being used to analyse the images obtained to assess the distribution and orientation of fibres in the concrete.

\section{Results and Discussions}

\section{A. Fresh Concrete}

The effects of inclusion of steel fibres in concrete on the workability of fresh steel fibre reinforced concrete was studied using slump test. Slump values were found to vary widely between $15 \mathrm{~mm}$ and $140 \mathrm{~mm}$ showing decrease in slump as dosages of fibre increased. It was also found that mixes with maximum coarse aggregate size of $20 \mathrm{~mm}$ generally show higher workability than mixes with $10 \mathrm{~mm}$ maximum aggregate size while the mixes of fibre length of $60 \mathrm{~mm}$ with $10 \mathrm{~mm}$ maximum aggregate size gave the least slump values of $15 \mathrm{~mm}$ and $18 \mathrm{~mm}$ at $60 \mathrm{Kg} / \mathrm{m}^{3}$ dosages. This may be attributed to the fact that the maximum aggregate size of $10 \mathrm{~mm}$ and steel fibre of $60 \mathrm{~mm}$ length could not interact properly because of discrepancies in the size/length combination of the two components thereby resulting sometimes in balling effect (formation of clumps of entangle fibres). Inclusion of steel fibres in concrete has been noted to generally reduce the workability of concrete as checked by slump test which is in agreement with other researched works, $[6,14]$.

\section{B. Compressive Strength}

The compressive strength results conducted showing the influence of steel fibres are given in Fig. 5 ( $a$ and b). The results generally show a slight improvement in the compressive strength of the mixes by the addition of steel fibres to concrete. The mean strength of SFRC varies between 57.7 to $69.9 \mathrm{MPa}$ and 58.1 to $68.1 \mathrm{MPa}$ for 10 and $20 \mathrm{~mm}$ aggregate sizes respectively while plain concrete had $53.23 \mathrm{MPa}$ for $10 \mathrm{~mm}$ maximum aggregate size and 60.69 $\mathrm{MPa}$ for $20 \mathrm{~mm}$ maximum aggregate size.

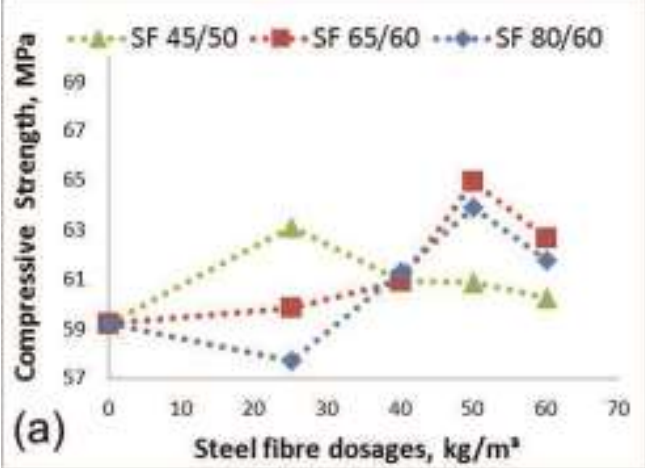

Figure 5a. Relationship between compressive strength and dosages of different fibres with $10 \mathrm{~mm}$ maximum aggregate size 
Proc. Of the International Conference on Advances in Civil, Structural and Construction Engineering - CSCE 2016 Copyright @ Institute of Research Engineers and Doctors. All rights reserved.

ISBN: 978-1-63248-101-6 doi: 10.15224/ 978-1-63248-101-6-10

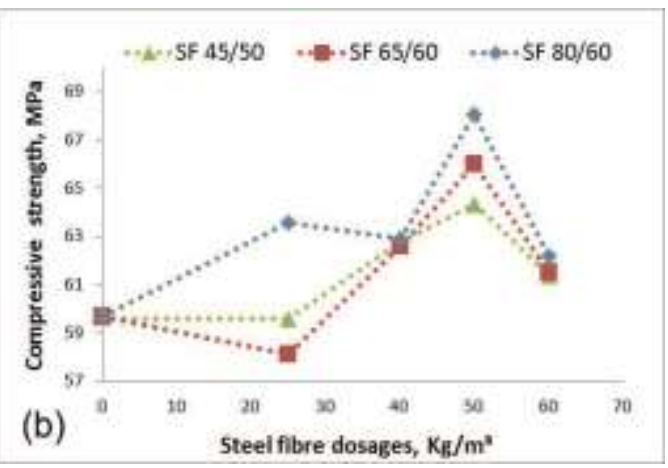

Figure $5 \mathrm{~b}$. Relationship between compressive strength and dosages of different fibres with $20 \mathrm{~mm}$ maximum aggregate size

The addition of steel fibres increased the compressive strength of the concrete in most cases while the compressive strength of plain concrete was in few cases higher than those of SFRC. The compressive strength of SFRC increases with increase in fibre dosage until optimum compressive was however achieved at $50 \mathrm{Kg} / \mathrm{m}^{3}$ dosages of steel fibre for both aggregate sizes after which it declined. This could be due to increase in air voids and decline in workability in concrete as the dosage increases which may also affect the interaction of fibres and aggregates and positioning of fibres within the SFRC.

\section{Flexural Properties}

The flexural strength of a notched beam determined by three-point bending tests shows that addition of steel fibres to concrete remarkably improves the flexural strength when compared to plain concrete as there were up to $83 \%$ and $54 \%$ increase in maximum strength reached for concrete with maximum course aggregate sizes of $20 \mathrm{~mm}$ and $10 \mathrm{~mm}$ respectively. Fig 6 ( $a$ and $b$ ) typically show the results of the flexural strength of plain concrete and that of dosages of SFRC with a particular steel fibre, 65/60, (meaning aspect ratio of 65 and length of $60 \mathrm{~mm}$ ). The results revealed that the higher the dosage, the better the flexural strength while high flexural strength is seen as depending on good selection of fibre geometry, dosage and mixture combination of aggregate within the concrete matrix that promote good interaction between the components for better positioning. This improves the post-cracking behaviour of SFRC.

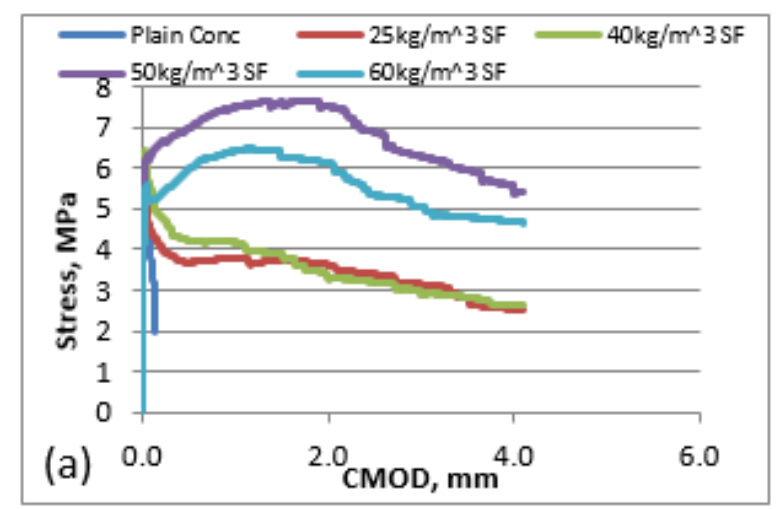

Figure 6a. Flexural strength of SFRC with dosages of 65/60 steel fibres in $10 \mathrm{~mm}$ aggregate size mix

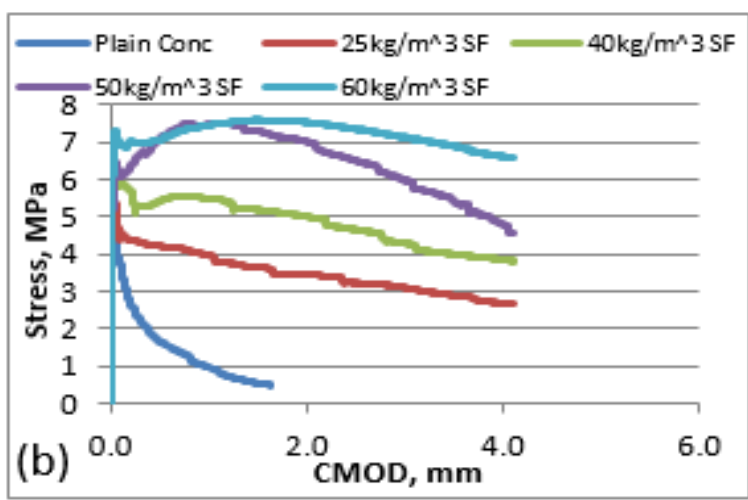

Figure $6 \mathrm{~b}$. Flexural strength of SFRC with dosages of 65/60 steel fibres in $20 \mathrm{~mm}$ aggregate size $\mathrm{mix}$

The $50 \mathrm{~kg} / \mathrm{m}^{3}$ dosage of steel fibre appears consistently superior in all the mixes and even with the higher dosage of $60 \mathrm{~kg} / \mathrm{m} 3$, the difference has not been significant. Fig. 7 shows all the mixes of both $10 \mathrm{~mm}$ maximum aggregate size and $20 \mathrm{~mm}$ maximum aggregate size at dosage $50 \mathrm{~kg} / \mathrm{m} 3$ for better comparison.

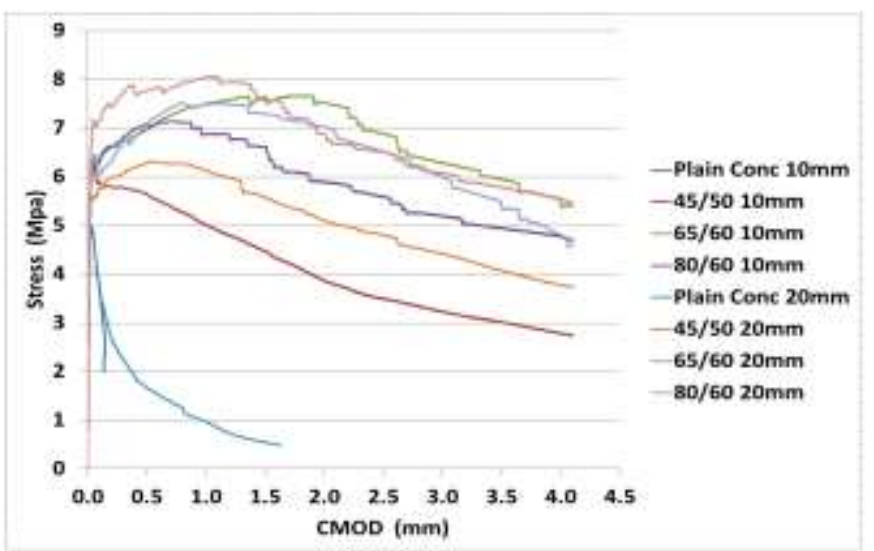

Figure 7. Flexural strength of plain concrete and SFRC at 50 $\mathrm{kg} / \mathrm{m} 3$ dosage

It could be noticed from the presented result in Fig. 7 that effectiveness of steel fibres in post-cracking ductility is dependent on aspect ratio as the highest flexural strength was exhibited by the beam containing fibres of highest aspect ratio of 80 . The length/aggregate size combination also resulted in good interaction which may affect the distribution and/or orientation of steel fibre within the concrete matrix. It was observed that the plain concrete failed in a brittle manner as soon as the cracks occurred while the steel fibre reinforced concrete exhibited a significant post-cracking strength with even higher strength above that of the first crack in this investigation, i.e strain hardening behaviour.

The square concrete slabs cast at $50 \mathrm{~kg} / \mathrm{m}^{3}$ fibre dosage were tested at 28 days. The results are summarised in Fig. 8 which shows the maximum loads the tested slabs could sustain before failure. Addition of steel fibres to the concrete slabs clearly improved the load carrying capacity of concrete. SFRC containing $10 \mathrm{~mm}$ maximum aggregate, fibres of length $60 \mathrm{~mm}$ and aspect ratio 65 had the highest load carrying capacity of all the slabs tested, $152 \%$ higher than that obtained by plain concrete. 
Proc. Of the International Conference on Advances in Civil, Structural and Construction Engineering - CSCE 2016 Copyright (C) Institute of Research Engineers and Doctors. All rights reserved.

ISBN: 978-1-63248-101-6 doi: 10.15224/ 978-1-63248-101-6-10

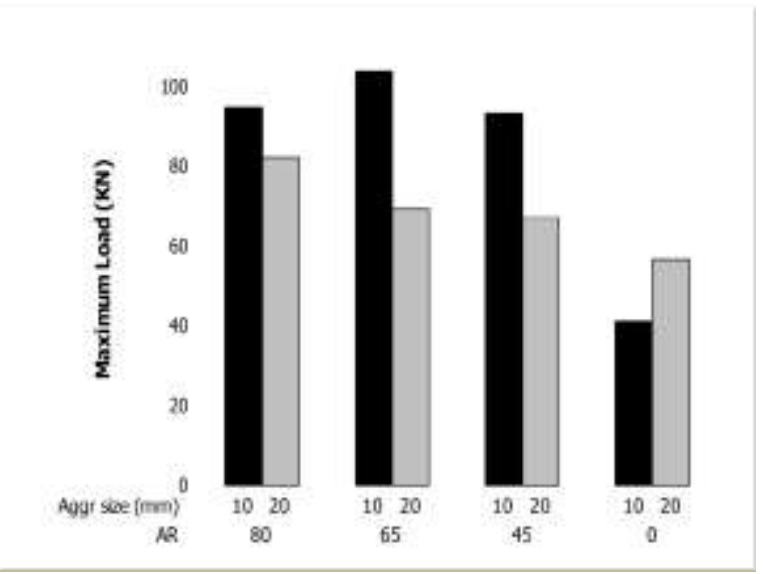

Figure 8. Maximum load of slabs with different aggregate size and fibre geometry at dosage $50 \mathrm{~kg} / \mathrm{m} 3$

The results also revealed mixtures of $10 \mathrm{~mm}$ coarse aggregate size outperforming the mixtures with $20 \mathrm{~mm}$ coarse aggregate size after the addition of steel fibres in the mix, whereas the plain concrete had the $20 \mathrm{~mm}$ aggregate mixture showing better load carrying capacity than $10 \mathrm{~mm}$ aggregate mixture.

\section{X-Ray Computed Tomography}

X-ray CT imaging method for obtaining internal microstructure of specimens was used to analyse the core samples that were extracted from the tested slabs to investigate the internal arrangement of steel fibres within the concrete matrix of the hardened SFRC materials. The X-ray imaging can be observed directly to view the arrangement of fibres within the concrete matrix as typically presented in Fig.9. The fibres show up as white elements all over the surface of the round horizontal slices as seen in Fig.9b and $9 \mathrm{c}$ which are slices from mixes of $10 \mathrm{~mm}$ maximum aggregate size containing fibres with aspect ratio/length of $65 / 60$ and 80/60 respectively. The shape of a fibre on these images provides information about its orientation relative to the plane of the image. Fibres lying close to parallel show as long ellipses while fibres lying perpendicular to the plane of the image (i.e. parallel to the axis of the core) show as circles.

The 3D view shown in Fig. 9a was achieved by the analysis carried out on a typical core combining all slices to visualise the positioning of the fibres within the SFRC core. Open source medical image processing $\mathrm{C}++$ libraries, The Insight Toolkit (ITK), [15] is being used to process the volumetric images acquired from $\mathrm{CT}$ scan presented in horizontal slices through the $100 \mathrm{~mm}$ diameter core at different heights. This is being developed to allow quantification of distribution and orientation of steel fibres within the whole core.

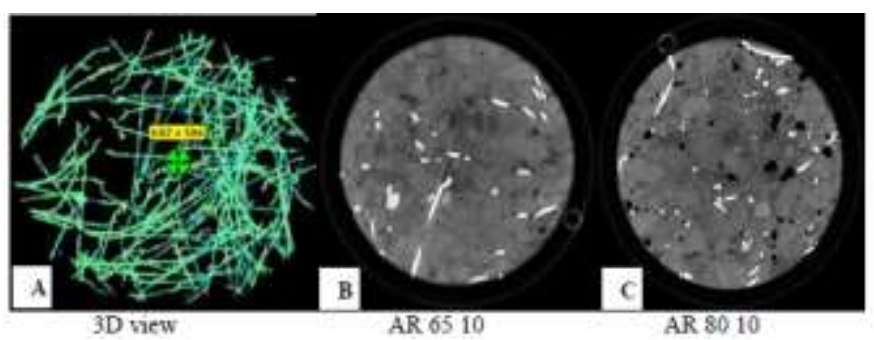

Figure 9. X-ray CT scan images of SFRC

\section{v. Conclusion}

Effects of inclusion of steel fibres in concrete remarkably improves the mechanical properties of concrete, especially the flexural properties while the compressive strength is slightly affected.

Outcome of the ongoing processing of CT scan images, with details of distribution/orientation of fibres in concrete matrix will be compared with mechanical performance results to finalise the correlation and effects of fibre positioning in concrete matrix on mechanical performance.

\section{References}

1. Bencardino, F., et al., Implications of test methodology on postcracking and fracture behaviour of Steel Fibre Reinforced Concrete. Composites Part B: Engineering, 2013. 46: p. 31-38.

2. Hannant, D.J., Fibre-reinforced concrete, in Advanced Concrete Technology, J.S.C. Newman, B, Editor. 2003: Burlington, USA.

3. Holschemacher, K., T. Mueller, and Y. Ribakov, Effect of steel fibres on mechanical properties of high-strength concrete. Materials \& Design, 2010. 31(5): p. 2604-2615.

4. Soutsos, M., T. Le, and A. Lampropoulos, Flexural performance of fibre reinforced concrete made with steel and synthetic fibres. Construction and Building Materials, 2012. 36: p. 704-710.

5. Wang, H. and L. Wang, Experimental study on static and dynamic mechanical properties of steel fiber reinforced lightweight aggregate concrete. Construction and Building Materials, 2013. 38: p. 11461151.

6. Soulioti, D., et al., Effects of Fibre Geometry and Volume Fraction on the Flexural Behaviour of Steel-Fibre Reinforced Concrete. Strain, 2011. 47(s1): p. e535-e541.

7. Barnett, S.J., et al., Assessment of fibre orientation in ultra high performance fibre reinforced concrete and its effect on flexural strength. Materials and Structures, 2010. 43(7): p. 1009-1023.

8. The Concrete Society, Guidance for the design of stell-fibrereinforced concrete. 2007: Camberley, Surrey.

9. Niwa, J., et al., Experimental Study on the Possibility of Using Steel Fiber-Reinforced Concrete to Reduce Conventional Rebars in BeamColumn Joints. Journal of Materials in Civil Engineering, 2012. 24(12): p. 1461-1473.

10. Alani, A.M., M. Aboutalebi, and M.J. King, Influence of fibre content on crack propagation rate in fibre-reinforced concrete beams. International Journal of Civil, Architectural Science and Engineering, 2013. 7(9): p. 117-123.

11. British Standards Institute, BS EN 197-1: Composition, Specifications and Conformity Criteria for Common Cements, in Part I: . 2011, BSI: London.

12. British Standards Institute, BS EN 14651:Test method for metallic fibre concrete. Measuring the flexural tensile strength (limit of proportionality (LOP), residual). 2005, BSI: London.

13. British Standards Institute, BS EN 14488-5:Testing sprayed concrete. Determination of energy absorption capacity of fibre reinforced slab specimens, in Part 5. 2006, BSI: London.

14. Taylor, M., F. Lydon, and B. Barr, Toughness measurements on steel fibre-reinforced high strength concrete. Cement and Concrete Composites, 1997. 19(4): p. 329-340.

15. Yoo, T.S., et al., Engineering and algorithm design for an image processing API: a technical report on ITK-the insight toolkit. Studies in health technology and informatics, 2002: p. 586-592. 